\title{
A Contribuição e Desafios da Administração Nacional de Medicamentos, Alimentos e Tecnologia Médica - Anmat - Ao Direito à Saúde dos Argentinos
}

\author{
CONTRIBUTION AND CHALLENGES OF ARGENTINE NATIONAL \\ ADMINISTRATION OF DRUGS, FOODS AND MEDICINE \\ TECHNOLOGY TO THE RIGHT TO HEALTH
}

Claudia Viviana Madies ${ }^{(*)}$

\section{RESUMO}

Este artigo se propõe a descrever alguns dos elementos explicativos do desenho da ANMAT, para uma aproximação a seu real funcionamento e identificação de parte de suas contribuições e desafios para melhorar o exercício do direito à saúde dos argentinos. O estudo começa analisando algumas das falhas de regulação a que está exposta tal administração e quais são as falhas do mercado específico da saúde que justificam sua existência. Em seguida aborda como o direito à saúde é reconhecido constitucionalmente na Argentina e de que modo o marco jurídico infraconstitucional prevê que essa agência regulatória favoreça o exercício desse direito. Destaca entre suas conclusões o desafio da agência de ser independente do poder político e das empresas reguladas, funcionando em um contexto de articulação e coordenação das políticas de saúde pública, com suficiente flexibilidade para adaptar-se às mudanças sociais e econômicas de uma sociedade moderna.

\section{Palavras-chave}

Agências Regulatórias; Direitos Humanos; Regulação Governamental; Vigilância Sanitária de Produtos.

(*) Advogada, especialista em Sistemas de Saúde e Seguridade Social da Universidad I Saúde, professora universitária, atualmente integra o gabinete de assessores do Ministério da Saúde da Argentina. E-mail: <madies.claudia@gmail.com>. Recebido em 31.8.09. 


\section{ABSTRACT}

This article aims to describe some of the explanatory drawing of ANMAT, an approximation to its actual operation and identification of some of their contributions and challenges to improve the right to health of Argentines. The study begins by analyzing some of the failures of regulation that is exposed such office and what are the specific market failures in health that justify its existence. Then it discuss how the right to health is constitutionally recognized in Argentina and how the law allows this agency to promote the exercise of that right. It highlights the challenge of this agency to be independent and flexible to adapt to social and economic changes in this society.

\section{Keywords}

Governmental Regulation; Human Rights; Regulatory Agencies; Sanitary Vigillance of Products.

\section{INTRODUÇÃO}

As indústrias farmacêutica e alimentícia assim como a tecnologia médica têm uma transcendência preponderante na sociedade moderna, pois favorecem a qualidade de vida da população, sobretudo após a II Guerra Mundial, quando o desenvolvimento tecnológico impactou tudo o que se vinculasse ao cuidado da saúde. O mercado dos medicamentos tem falhas específicas que forçam o Estado a intervir em sua produção e financiamento, assim como em sua regulação e fiscalização. Verifica-se essa hipótese tanto em relação aos preços, qualidade, eficácia e segurança, como à sua publicidade e inclusive ao que se refere aos incentivos adequados para as inovações.

No contexto da função reitora em saúde do Estado, a regulação é a dimensão que abarca o desenho do marco normativo sanitário que protege e promove a saúde e a garantia de sua realização. ${ }^{(1)}$ Segundo a seguinte definição operativa, regulação é a função de:

1) Estabelecer:

a) Regras e padrões (protocolos, guias, manuais que podem ou não ser obrigatórios, mas que se constituem na base da norma jurídica) e

b) Normas jurídicas de caráter obrigatório (por meio de leis e regulamentos), às que devem ajustar-se as pessoas (naturais ou jurídicas), os bens e os serviços, a fim de proteger a saúde e permitir o acesso equitativo e universal à saúde;

(1) OPS y USAID. Función rectora de la Autoridad Sanitaria Nacional: desempeño y fortalecimiento. Edición Especial No. 17. Washington, D. C., 2007, p. 10. 
2) Assegurar mecanismos transparentes e eficientes de controle e fiscalização do cumprimento dos pontos 1 a) e b) ${ }^{(2)}$.

Não há duvida de que, para proteger os cidadãos, os Estados criam órgãos de regulação e fiscalização, o que em matéria de medicamentos inclui fundamentalmente a outorga de licenças, inspeções de fabricação, distribuição, assessoramento e registro de produtos, monitoramento de reações adversas às drogas, controle de qualidade, promoção e publicidade e supervisão de ensaios clínicos.

Em alguns países tudo o que se refere à fiscalização e controle dos medicamentos é competência de uma única agência, em outros países, de dois ou mais organismos, inclusive em distintos níveis de governo.

A OMS sugere para o controle e vigilância dos medicamentos uma agência reguladora nacional. No Chile, o Departamento de Control Nacional del Instituto de Salud Pública, no Brasil, Agência Nacional de Vigilância Sanitária (ANVISA), na Espanha, a Agência Española de Medicamentos y Productos Sanitarios, nos Estados Unidos, a Food and Drug Administration e na Argentina, a Administración Nacional de Medicamentos, Alimentos y Tecnología Médica (ANMAT) ${ }^{(3)}$.

O surgimento das agências reguladoras independentes foi comum nos últimos 20 anos na Europa e América Latina, quando das privatizações, e, teoricamente, tais agências conformam uma condição de bons resultados da atividade reguladora, que supostamente se transferem aos consumidores. A maioria das agências regula qualidade, segurança e eficácia, e tem indicadores para medir sua gestão, desempenho e execução orçamentária. Para uma adequada regulação, é claro que deve haver um marco jurídico normativo preciso, pessoal especializado, fundos suficientes, necessários recursos de infraestrutura, guias e manuais de procedimentos específicos e padrões de implementação definidos.

A intervenção pública por meio de instrumentos reguladores está ligada à noção de interesse público. Mediante políticas reguladoras se usa o poder coercitivo do Estado para estabelecer as "regras do jogo" do mercado, evitando que se produzam condutas abusivas dos agentes dominantes sobre os demais atores na arena setorial. Para isso é vital possuir, entre outras, a capacidade e habilidade para exercitar essa ação reguladora independentemente da dinâmica da interação política inerente ao sistema democrático. Por isso mesmo é cada vez mais comum distribuir as competências

(2) A definição adotada corresponde à acordada durante a Reunión para la Creación de la Red Latinoamericana de Autoridades de Salud Pública en Regulación y Fiscalización (REG SAÚDE), em Havana, Cuba, em 22 e 23 de março de 2007, com a participação de Argentina, Colômbia, Cuba, El Salvador, Honduras, Nicarágua e Paraguai.

(3) BARBIERI, Eugenia; BUMBAK, Sonia y PERALTA, Martín. ANMAT-INPI. Organización, estructura y experiencias internacionales. Com coordenação de Daniel Maceira. Buenos Aires: CIPPEC, 2008. 
reguladoras entre distintos organismos públicos, uns encarregados do desenho e planificação da política pública e outros do controle e das garantias de cumprimento das regras do jogo. Os primeiros estão nos âmbitos ministeriais e os segundos nos organismos de controle independentes da hierarquia executiva ${ }^{(4)}$.

No caso da Argentina, no que se refere à garantia da eficácia, segurança e qualidade dos medicamentos, a ANMAT é a responsável, enquanto outra agência descentralizada, o Instituto Nacional de Propiedad Industrial (INPI) é o organismo que protege as inovações, entre as quais estão as farmacêuticas. Destaque-se que a indústria local argentina conseguiu articular esforços para inserir-se neste mercado num marco regulatório que favoreceu o registro de produtos similares aos inovadores, caso tenham sido aprovados para o consumo em países de alta vigilância sanitária. Para isso a ANMAT cumpre regulações que são do nível de decreto ou lei.

Não se pode esquecer que a razão de ser da criação deste tipo de entes estatais é corrigir falhas de mercado frente às fortes assimetrias de poder que existem entre os regulados e os consumidores, porém a regulação em si mesma também encerra falhas referidas ao manejo de informação dos processos regulatórios. Daí a importância de que este tipo de agência seja independente do poder político e das empresas reguladas e a par disso funcionem em um contexto de articulação e coordenação das políticas de saúde pública, com a suficiente flexibilidade para adaptar-se às mudanças sociais e econômicas das sociedades modernas.

\section{FALHAS DE MERCADO E FALHAS DE REGULAÇÃO}

A intervenção do Estado sobre as decisões do mercado, os preços ou as barreiras de entrada e saída desse mercado tem como fundamento corrigir as múltiplas falhas desses mercados ou quase mercados que se consideram imperfeitos sob a ótica da teoria econômica. Entre as falhas dos mercados de saúde ${ }^{(5)}$ que as regulações como resposta institucional procuram corrigir, se encontram:

1 - A incerteza de adoecer e a incidência da enfermidade constumam gerar como resposta institucional e regulatória o mecanismo de asseguramento, com o fim de evitar: a) a seleção adversa como mecanismo

(4) SANCHO, David. Regulación y agencias reguladoras independientes: elementos claves para la consolidación de su diseño institucional. Conferência apresentada no VIII Congreso Internacional. Reforma del Estado y Administración Pública. CLAD. Panamá. 28-31 Octubre de 2003.

(5) PROBST, Jeacqueline Marie; MADIES, Claudia Viviana. Fortalecimiento de la rectoría de la autoridad sanitaria nacional: evaluación y fortalecimiento de la regulación y de fiscalización (versión preliminar). Coordenado por Mónica Bolis. Washington D. C.: OPS Area de Sistemas y Servicios de Salud, 2008. 
pré ou pós-contratual de ocultamento de informação e b) o abuso moral e desnecessário no uso das prestações ou produtos por parte do usuário ou consumidor.

2 - A incerteza sobre a efetividade do tratamento, que tem como resposta institucional a regulação do exercício profissional e pode ter como efeito secundário ou gerar um monopólio ou estabelecer barreiras de entrada ao ingresso na profissão ou especialidade.

3 - A assimetria de informação que existe entre o profissional da saúde e o paciente em que a resposta institucional se configura na relação de agência que explica que o médico atue adequadamente sub-rogando-se na decisão do paciente. Tal sub-rogação pode ser imperfeita quando o médico considera para a decisão variáveis que não afetam ao paciente, mas a ele mesmo, gerando uma demanda que está induzida pelo profissional em seu próprio benefício.

4 - As externalidades ou bens públicos entendidos como benefícios ou prejuízos que se causam a um terceiro em consequência da produção de um bem ou serviço. Por exemplo, frente a doenças transmissíveis, a investigação, o meio ambiente, a resposta institucional mais conhecida é subsidiar a vacinação, seguros etc., ainda que possa aparecer um efeito secundário, que é haver pessoas que não queiram vacinar-se ou serem subsidiadas. Também se poderia ter como resposta institucional a correta assignação de direitos de propriedade, sem subsídios do Estado, ainda que isso seja difícil de implementar.

5 - Os bens tutelares que são aqueles cujo consumo deve ser protegido pelo Estado.

6 - Os mercados incompletos que se verificam quando há gente disposta a pagar, porém ninguém quer assegurar sua cobertura. Neste caso a resposta institucional pode ser a provisão direta por parte do Estado.

7 - Os rendimentos crescentes que se verificam quando há economias de escala, que ocorrem, por exemplo, em localidades de baixa densidade de população onde seria razoável que não existisse mais de um provedor.

Além disso, a teoria econômica reconhece que junto às imperfeições do mercado e suas respostas institucionais para buscar sua eficiência, em saúde se verificam falhas normativas ou regulatórias positivas ou negativas. Entre as primeiras se encontram a busca da equidade ou a proteção dos bens públicos, que por serem os mais importantes para um país devem ser cuidados, pois guardam relação com a valoração que deles faz cada sociedade e que surgem do mercado ou tendem à sua eficiência. 
Agora bem, a existência de um regulador ${ }^{(6)}$ supõe que ele seja um sujeito benevolente que impedirá que os agentes com poder de mercado afetem o bem-estar da sociedade, por meio de atividades que gerem benefícios privados. Este regulador deve deixar operar a empresa regulada de modo tal que não se aproprie por completo do excedente do consumidor. Por exemplo, ao fixar tarifas aos entes regulados deve ter em conta dados de custos dessas mesmas empresas reguladas, existindo, desde a teoria econômica, distintas formas de fixá-las. Porém a regulação também pode ter suas próprias falhas, vinculadas aos custos sociais, pois pode estabelecer-se uma relação de agência entre o regulador (principal) e a empresa regulada (agente).

Além disso, pode-se verificar uma inconsistência dinâmica, dadas as dificuldades do regulador para operacionalizar as políticas ótimas em diferentes períodos de tempo, o que demanda por parte do regulador compromissos viáveis e sustentáveis no tempo para que os regulados invistam em níveis ótimos. Também pode acontecer de as empresas reguladas darem informação enviezada ao regulado e verificar-se a captura do regulador por parte dos grupos de interesses, procurando o regulador então maximizar o interesse político a favor de seus interesses individuais, em lugar de fazê-lo em favor do bem-estar social.

Costuma acontecer que o organismo regulador, que surge por necessidade da administração, acaba sendo acolhido no seio da atividade que há de regular. Não obstante, essa independência do regulador tampouco deve representar o desconhecimento de uma política pública ou de Estado orientada a melhorar esse bem-estar social, por cima das preferências setoriais.

O grau de independência dos entes reguladores varia de um país a outro, principalmente pelas características institucionais básicas, as atribuições dadas ao organismo, o pessoal qualificado e os recursos disponíveis.

$\mathrm{Na}$ Argentina, diferentemente das outras agências regulatórias mencionadas na introdução deste estudo, a ANMAT não realiza a inspeção e controle do canal de distribuição de medicamentos integralmente (tarefa desempenhada pelo Programa de Pesquisa de Medicamentos llegítimos), tampouco controla preços (como faz a ANVISA), nem intervém no processo de outorga de patente (diferentemente do Brasil, onde se reconhece à instancia sanitária a oportunidade de participar do procedimento de anuência prévia). Em relação ao número de habitantes da Argentina, comparativamente, o pessoal da ANMAT é menor que o de sua contraparte no Chile, por exemplo. Por outra parte, comparativamente com outros países da região, a ANMAT demora mais tempo para tramitar o registro de novas drogas que o Chile ou o Brasil.

(6) SIFONES, Domingo. Regulación Económica y Agencias regulatorias independientes: una revisión de la literatura. Revista Virtual Contribuciones a la Economía. Disponível em: <http://eumed.net/ce/ ds-regulat.htm>. 
Vale destacar que o mercado de produção de medicamentos no país é composto por fabricantes de princípios ativos e de fórmulas farmacêuticas. $\mathrm{Na}$ comercialização dos fármacos há um sistema de venda ao público que não difere do de outros produtos, verificando-se também a conformação de cadeias de farmácias.

As instâncias com as quais a ANMAT teve ou tem conflitos de competência, e que são também instâncias regulatórias e/ou fiscalizadoras, são, por exemplo, o Servicio Nacional de Sanidad y Calidad Agroalimentaria (SENASA), a Dirección Nacional de Fiscalización y Sanidad de Fronteras, o INPI, o Instituto Nacional Central Unico Coordinador de Ablación e Implante (INCUCAI), o Plan Nacional de Sangre, entre outras. Nem todas elas se encontram sob a órbita do Ministerio de Salud de la Nación, algumas dependem de outras carteiras nacionais, isso sem considerar o que sucede com as instâncias provinciais.

A ANMAT cumpre normas ditadas pelo governo, resolve disputas entre operadores ou nelas intervém e não cuida da concorrência no setor ao não intervir nem nela nem na fixação de tarifas, que são em definitivo os temas que maior repercussão têm sobre os consumidores. Sua função regulatória cede ante sua função fiscalizadora.

\section{O DIREITO CONSTITUCIONAL À SAÚDE E À ELABORAÇÃO E COMERCIALIZAÇÃO DE PRODUTOS PARA A SAÚDE}

Nos últimos anos, com as reformas constitucionais de muitos dos países da região, se verificou um maior reconhecimento do direito à saúde e, para torná-lo efetivo, tomaram maior transcendência as regulações. A eficácia da função regulatória tem sido condicionada, entre outros fatores, pelos déficits na gestão da modernização em geral do Estado e as consequências de sua falta de coerência, viabilidade, factibilidade e, inclusive, pela imprevisibilidade das falhas que as próprias regulações podem ter causado ${ }^{(7)}$.

A partir de 1980 a saúde ingressa nas agendas políticas como um direito, ao ser reconhecida legal e constitucionalmente e serem criados os mecanismos legais para reclamar sua vigência. É óbvio, entretanto, que para tornar-se efetiva a vontade política deve estar acompanhada do desenvolvimento das capacidades institucionais respectivas para a consecução do respeito e o cumprimento do direito. Assim, tal como sugere o informe preliminar de um estudo da Organização Panamericana da Saúde para o Fortalecimento da Reitoria da Autoridade Sanitária Nacional:

(7) PROBST, Jeacqueline Marie y MADIES, Claudia Viviana. op. cit. 
...Para que uma boa gestão em saúde contribua para superar a situação de alta iniquidade que se evidencia nossa Região, fica claro que no desenho macroeconômico é fundamental o papel do Estado, que inclua nas políticas de saúde previamente definidas e a serem implementadas a necessidade de corrigir as múltiplas falhas que têm, em maior ou menor medida, os sistemas regulatórios da Região, sendo as principais $^{(8)}$ :

- Objetivos de políticas sanitárias ou de regulações pouco claros.

- Confrontação de interesses e objetivo das instâncias regulatórias.

- Discricionariedade por ausência de parâmetros técnicos.

- Vazios de capacitação.

- Déficits de manuais de procedimentos.

- Falta de articulação e coordenação para garantir viabilidade.

- Clientelismo político e falso protagonismo político.

- Submissão a pressões externas nacionais ou internacionais.

- Falta de comunicação e de informação veraz e oportuna.

- Riscos de corrupção por captura do regulador ou fiscalizador.

- Baixa eficiência ou eficácia por excesso ou falta de regulação ou contradições, vazios, inconsistências ou incongruências das regulações.

- Ausência ou limitada efetividade das sanções.

- Déficits nas áreas de apoio administrativo ou de sistemas tecnológicos.

- Limites ao efetivo exercício dos direitos da população.

Seguindo o referido estudo:

...Os déficits nas capacidades vinculadas à liderança e reitoria em saúde ou a escassa capacidade para a gestão administrativa (falhas de comunicação, coordenação, planificação, otimização de recursos) em distintos níveis e na definição dos princípios reitores e valores dos sistemas de saúde impactam na consequente deterioração do compromisso por parte dos atores setoriais ou no pouco empoderamento de direitos da sociedade, que, em definitivo, é o que legítima a função de reitoria(9).

Os marcos jurídicos normativos e as protocolizações e guias para a melhora dos processo de qualidade, entre outras, são importantes fer-

(8) Id. Ibid.

(9) Id. Ibid. 
ramentas para instrumentar as transformações do setor saúde, porém nem sempre se prestou a devida atenção às capacidades necessárias para sua formulação, implementação e seguimento, o que condiciona sua efetividade, qualidade e eficácia.

Por outro lado, além da morfologia e interinstitucionalidade do setor, exercem influência distintiva no processo regulatório o caráter federal ou unitário da organização política dos países. $O$ exposto exige diferenciados e particulares esforços da autoridade reitora para definir suas políticas, coordená-las e articulá-las, em especial, com relação à função de regulação e fiscalização. Isso demanda dos Estados federais implementar políticas compensatórias e redistributivas entre regiões, conservando a formulação da organização geral do sistema, com amplos espaços institucionalizados de negociação, e uma proba capacidade para induzir a transformação do modo de gestão sanitária. Existe, portanto, clara diferença com os Estados unitários, dado que eles podem desconcentrar funções ou avocá-las com maior facilidade ${ }^{(10)}$.

Neste contexto, a discricionariedade dos entes regulatórios deve ser importante em setores com rápidas mudanças tecnológicas, nos quais a introdução da competitividade requer adaptar-se às condições de mercado. É preciso, contudo, manterem-se isolados da pressão política, sendo a prestação de contas a alternativa para isso, pois obriga o regulador a ser responsável no exercício da função reguladora com respeito à opinião pública. ${ }^{(11)}$

Um regulador independente é um déficit democrático dado que não é eleito. Assim, a prestação de contas periódica à cidadania e aos representantes eleitos democraticamente busca diminuir tal déficit, dando transparência ao processo regulador. Faz parte dessa prestação de contas a proibição de conflito de interesses, a obrigação de difundir as atas de reunião dos corpos diretivos dos entes reguladores ou seus atos administrativos, que devem ser acompanhadas de outras medidas, como evitar que o regulador por um tempo trabalhe para a empresa regulada, uma vez afastado. ${ }^{(12)}$

Na Argentina, com a reforma constitucional de 1994, se reconhece aos Tratados Internacionais de Direitos Humanos valor constitucional (art. 75, inciso 23). Entre tais tratados, com relação ao direito à saúde, se destaca a Declaração Universal de Direitos Humanos, o Pacto Internacional de Direitos Econômicos, Sociais e Culturais, e a Declaração Americana dos Direitos e

(10) Id. Ibid.

(11) Id. Ibid.

(12) Id. Ibid. 
Deveres do Homem, assim como o art. 42 da Constitução. Este artigo aprofunda o direito da população consumidora, quando diz que

Os consumidores e usuários de bens e serviços têm direito, na relação de consumo, à proteção da saúde, segurança e interesses econômicos; a uma informação adequada: à liberdade de eleição e a condições de trato equitativo e digno. As autoridades proverão a proteção desses direitos, a educação para o consumo, a defesa da concorrência contra toda forma de distorção dos mercados.

Em consequência, os problemas de resistência a certos medicamentos, as imperfeições dos já existentes e as doenças-órfãs de medicamentos preventivos ou curativos, entre muitos outros problemas vinculados à saúde pública, são aspectos que obrigam a ANMAT a contribuir para sua solução e desse modo tornar efetivo o direito à saúde dos argentinos.

Sobre a capacidade técnica do organismo, precisamente em matéria de medicamentos, é válido precisar que o Instituto Nacional de Medicamentos (INAME), que faz parte da ANMAT, obteve várias distinções, entre elas o "Prêmio Nacional de Qualidade" do setor público, em 2003 e em 2005. A Organização Panamericana da Saúde o categorizou no mais alto nível por seus parâmetros de qualidade e foi selecionado como laboratório de referência dessa Organização. Tudo isso reflete que o organismo é reconhecido por sua ingerência na garantia da segurança, eficácia e qualidade dos produtos que regula e, por isso, na sua função específica, segundo seus objetivos institucionais, tal como se enunciam no capítulo seguinte.

Por outra parte, o federalismo, que surge da repartição constitucional de competências entre a Nação, as Províncias e a Cidade Autônoma de Buenos Aires, e impera na Argentina, determina que em matéria de exercício do poder de polícia sanitário a função de fiscalização é dever das jurisdições locais, dado que não foi delegada para a Nação. Assim, a competência da ANMAT se circunscreve às questões que envolvem dependências do Estado Nacional ou ao trânsito interjurisdicional ou internacional dos produtos regulados. Não obstante, essa Administração impulsionou, uns poucos anos atrás, a criação de uma rede federal de fiscalização, a fim de melhorar a articulação do exercício de sua função com seus pares provinciais.

Em consequência, a ANMAT celebrou várias Cartas-Compromisso com o Cidadão, no marco de uma iniciativa impulsionada pela Subsecretaria da Função Pública, dependente da Chefatura de Gabinete de Ministros, compreendendo mecanismos de consulta e participação da cidadania. Eles se restringem a sistemas de queixas, reclamações e sugestões ou pesquisas de satisfação, e não existe regulado um sistema de prestação de contas ou de audiências públicas, nem tampouco levantamentos de expectativas entre os profissionais da saúde ou consumidores. 


\section{A ANMAT E OS ANTECEDENTES DE SUA CRIAÇÃO PELO DECRETO N. 1490/92}

Vigiam na Argentina no período anterior à criação da ANMAT o Reglamento Alimentario (criado pelo Decreto n. 141/53, que pela Lei n. 18284, em 1969 muda para Código Alimentario Nacional) e a Lei n. 16463 de 1964 (que regula a importação, exportação, produção, elaboração, fracionamento, comercialização e depósito de drogas, medicamentos e todo outro produto de aplicação em medicina humana), regulamentada pelo Decreto n. 9763/64, para a área de medicamentos, e sobre produtos médicos, em 1985, pelo Decreto n. $2505^{(13)}$.

A transformação econômica, com a abertura de novos mercados e o episódio de intoxicação, por ingesta do produto Propóleo que causou 23 mortes, em 1992, tornou necessário aperfeiçoar as medidas para exercer controle estrito sobre a elaboração e o consumo de medicamentos que garantissem a segurança sanitária da população, e motivou o Poder Executivo Nacional a editar o Decreto n. $1490 / 92^{(14)}$.

No art. $1^{\circ}$ do Decreto n. 1490/92, se declararam de interesse nacional as ações dirigidas à prevenção, resguardo e atenção da saúde da população, que se desenvolvem por meio do controle e fiscalização da qualidade e sanidade dos produtos, substâncias, elementos e materiais que se consomem ou se utilizam na medicina, cosmética e alimentação humana.

Em seguida, no art. $2^{\circ}$ do mesmo Decreto se criou a ANMAT, como organismo descentralizado da Administração Pública Nacional, dependendo técnica e cientificamente da Secretaría de Salud (hoje Secretaría de Políticas, Regulación e Institutos), como Autarquia Financeira e Econômica e com jurisdição em todo o território da Nação.

Em decorrência, como ente descentralizado, a ANMAT possui personalidade jurídica própria, vinculação legal de recursos, patrimônio estatal, capacidade de administrar-se, foi criada pelo Estado e está submetida a seu controle.

Esse controle estatal se estende ao orçamento e aos investimentos por meio da Sindicatura General de la Nación (organismo de controle interno) e da Auditoria General de la Nación (organismo de controle externo), à designação de suas autoridades, assim como ao controle de seus atos administrativos quando terceiros por eles afetados interpõem os recursos autorizados pelo ordenamento jurídico e, excepcionalmente, e em casos muito graves, sua intervenção(15).

(13) Cuarta Carta Compromiso con el Ciudadano de ANMAT. Argentina, 2007.

(14) DONATO, Nora. ANMAT, La descentralización institucional en el ejercicio de la función de regulación y fiscalización. Las agencias. Conferência apresentada no Curso Taller Internacional de Derecho Sanitario. Fortalecimiento de la Función Regulatoria de Salud, OPS- CEPEDISA- FIOCRUZ, Brasilia, 9-13 jun. 2008.

(15) Id. Ibid. 


\section{MISSÃO, VISÃO E COMPETÊNCIAS}

A ANMAT tem como missão realizar as ações conducentes ao registro, controle, fiscalização e vigilância da qualidade e sanidade dos produtos, substâncias, elementos, processos, tecnologias e materiais que se consomem ou utilizam na medicina, alimentação e cosmética humanas e controlar as atividades e processos que medeiam ou estão compreendidos nessas matérias. Garante que os produtos possuam eficácia (cumprimento do objetivo terapêutico, nutricional ou diagnóstico), segurança (alto coeficiente benefício/risco) e qualidade (cumprimento dos padrões preestabelecidos).

A visão desse organismo com filosofia gerencial está orientada para a qualidade num ambiente de criatividade e inovação, gestão orientada para os valores de transparência, credibilidade, preditibilidade, eficiência e focada para satisfazer as necessidades do cidadão, por meio da implementação de um sistema de inspeção, vigilância e controle.

São competências da ANMAT o controle da sanidade e qualidade de drogas, produtos químicos, reativos, fórmulas farmacêuticas, medicamentos, elementos de diagnóstico, materiais e tecnologias biomédicas e todo outro produto de uso e aplicação em medicina humana. Também, de alimentos acondicionados, insumos específicos, aditivo-colorantes, edulcorantes e ingredientes utilizados na alimentação humana, produtos de uso doméstico e materiais em contacto com alimentos, produtos de higiene e tocador, cosmética humana, drogas e matérias-primas que os compõem.

Do mesmo modo, compete à ANMAT a vigilância da eficácia e detecção dos efeitos adversos que resultem do consumo e utilização dos produtos, elementos e materiais compreendidos anteriormente. $\mathrm{O}$ controle de processos, atividades e tecnologias que se realizem em função do aprovisionamento, produção, elaboração, fracionamento, importação e/ou exportação, depósito e comercialização dos produtos antes enumerados.

A ANMAT é competente para o trânsito interprovincial, não para produtos elaborados e comercializados dentro de uma mesma jurisdição. Mais recentemente surgiu a rede federal de fiscalização, que hoje é coordenada pela ANMAT, por intermédio do Conselho Federal de Saúde integrado por todos os Ministros de Saúde das províncias argentinas e da Cidade Autônoma de Buenos Aires e que é presidido pelo Ministro de Saúde da Nação.

\section{DO MODELO REGULADOR AO FISCALIZADOR}

A função regulatória em matéria de saúde pública implica um processo em que participa a autoridade competente. Compreende o desenho, a elaboração de normas, e as medidas que facilitem sua efetiva 
aplicação, assim como o seguimento, controle, fiscalização e auditoria de seu efetivo cumprimento. Em consequência, compreende(16):

- A capacidade institucional para desenvolver o marco regulatório necessário para monitorar e proteger a saúde da população. Envolve recolher as opções majoritárias da sociedade com respeito à matéria a regular e priorizar objetivos; é de caráter mais político.

- A capacidade para propor novas leis e emitir regulações dirigidas a melhorar a saúde da população e promover entornos saudáveis. Exige excelência e conhecimento técnico no desenho de normas, para que cumpram eficientemente o objetivo planejado.

- Os mecanismos institucionais para a proteção da população e sua relação com o sistema de saúde, contribuindo para a equidade geográfica. Isto exige domínio para a negociação interjurisdicional, o desempenho das funções que não são exercidas por outros atores sociais ou níveis de governo, e sobre os mecanismos de participação e reclamação eficazes a favor da comunidade.

- A execução e fiscalização dessas atividades para assegurar o cumprimento das regulações e normas em forma oportuna, correta e congruente, e de maneira integral. Esta é uma função essencialmente técnica, que demanda especialização profissional e comprovada independência de interesses em relação aos fiscalizados. Depende fortemente da disponibilidade de recursos humanos e técnicos e do reconhecimento normativo das atribuições sancionatórias respectivas. Essas, sem prejuízo de garantir o direito ao devido processo dos eventuais infratores, devem ter certa relação de mediata temporalidade com a falta, pois o bem em jogo é a saúde. Também requer políticas compensatórias orientadas a promover o desenvolvimento de melhorias.

Esse conjunto de mecanismos e capacidades que caracteriza a função regulatória está condicionado pela existência de representatividade política e social, solvência e autoridade técnica, mecanismos que resguardem a transparência e a firme vontade política de submeter-se ao escrutínio social.

Os indicadores que permitem medir seu desempenho são a revisão periódica, avaliação e modificação do marco regulador, o efetivo cumprimento, os conhecimentos e aptidões para revisar e aperfeiçoar o marco regulatório, a assessoria e apoio aos entes subnacionais e a geração e fiscalização de novas leis e regulamentos. ${ }^{(17)}$

(16) Con base en OPS/OMS. La saúde pública en las Américas: nuevos conceptos, análisis de desempeño y bases de acción. Publicación Científica y Técnica No. 589. Washington, D. C.: OPS/ OMS, 2002.

(17) Id. Ibid. 
Até a sanção do Decreto n. 150/92 e a posterior criação da ANMAT, o modelo regulatório adotado gozava de baixa eficácia, eficiência e transparência já que os recursos humanos e infraestrutura estavam dirigidos para a avaliação da informação apresentada pelos laboratórios sem realizar a respectiva fiscalização direta sobre os produtos no mercado(18).

Em consequência, nos casos em que era preciso tomar medidas de impacto (proibição de comercialização, interdições, alertas etc.) era necessário utilizar recursos não disponíveis com um alto custo operativo, o que levava a uma grande burocratização do sistema em prejuízo da transparência.

Com o novo modelo fiscalizador, instituído pelo Decreto n. 150/92 num mercado desregulado, os recursos existentes - humanos, econômicos e de infraestrutura - se puseram à disposição da fiscalização e controle (verificação, inspeção, controle de qualidade etc.). Sua própria dinâmica lhes permite lograr maior eficiência com o aproveitamento dos recursos vinculados, com conquistas concretas, mensuráveis e avaliáveis. Tende-se, assim, ao alcance de uma gestão mais transparente num sistema controlado, em contacto direto com a realidade da qualidade dos produtos.

Assim, a ANMAT autoriza e inscreve especialidades medicinais e verifica e controla eficácia, segurança e qualidade. Também o acesso é fundamental e foi como se instituiu a política do uso do nome genérico dos medicamentos, em que a ANMAT desempenhou função transcendente.

Pelo menos uma vez ao ano se inspecionam os estabelecimentos para verificar que cumpram as BPFeC e as inspeções são aleatórias. Também, o programa de pesquisa de medicamentos ilegítimos, em 14.000 pontos de venda de todo o país, vem retirando medicamentos não autorizados, com apoio da indústria ${ }^{(19)}$.

\section{A PROMOÇÃO DO ACESSO AOS MEDICAMENTOS, O CONTROLE DE SUA PUBLICIDADE E A PARTICIPAÇÃO DO SETOR REGULADO}

A denominação comum internacional, como verdadeiro nome dos medicamentos, é a denominação com que eles são conhecidos e divulgados nos meios científicos e acadêmicos. É a maneira de nomeá-los recomendada pela Organização Mundial da Saúde (OMS), faz referência ao princípio ativo contido na especialidade farmacêutica.

A Organização Mundial da Saúde e a Organização Panamericana da Saúde (OPS) reconhecem, em suas práticas e documentos, que uma política

(18) DONATO, Nora. op. cit.

(19) BARBIERI, Eugenia; BUMBAK, Sonia y PERALTA Martín. op. cit. 
de medicamentos essenciais tem importância estratégica para garantir o acesso e o uso racional dos produtos farmacêuticos.

Na Primeira Conferência Latino-Americana sobre Aspectos Econômicos e Financeiros dos Medicamentos - realizada em Caracas em março de 1992 - se recomendou a adoção de programas de medicamentos genéricos como ponto central da estratégia de acesso(20). E assim o uso do nome genérico dos medicamentos foi regulado na Argentina por lei e seu decreto regulamentador, mediante normas que previram regulação do exercício profissional médico e farmacêutico, defesa do consumidor e publicidade de medicamentos. O controle da publicidade dos medicamentos por parte da indústria também é regulado pela ANMAT, em função das previsões da Lei n. 16.463 de medicamentos, da Resolução M.S. 2005 e de Disposições da ANMAT.

Caracteriza a gestão da ANMAT sua filosofia institucional de governo aberto inovador e participativo. Em meados de 2007, seus regulados, em torno de 610 empresas, consultam seus trâmites na ANMAT pela internet, com um volume de consulta em 18 meses de cerca de 51.000 expedientes; período que registrou cerca de 2.150 .000 acessos $^{(21)}$.

\section{DESAFIOS DA ANMAT}

A ANMAT autodefine seus desafios como aprofundar a descentralização por meio da modificação normativa (criação da ANMAT por lei), tornar efetiva a autarquia financeira e econômica, criar novos cargos na estrutura permanente da organização, e incrementar suas atribuições e competências, instando a edição de normas específicas ${ }^{(22)}$. Isso inclui a revisão técnica do Registro de Especialidades Medicinais tendente à sua progressiva racionalidade e a fortalecer os programas de capacitação contínua do pessoal técnico e administrativo.

Na Quarta Carta Compromisso com o Cidadão (2007), a ANMAT predisse que face a sua presença fiscalizadora, pelo alcance da relação entre as fiscalizações/sanções, tal relação tenderá a zero no tempo, considerando que o numerador são as sanções aplicadas e o denominador as fiscalizações realizadas, por ser essa a tendência que se verifica em outras agências similares ${ }^{(23)}$. Sobre este ponto é importante aclarar que não se conta entre as funções da

(20) DONATO Nora. ANMAT. op. cit.

(21) Id. Ibid.

(22) Id. Ibid.

(23) CUARTA Carta Compromiso con el Ciudadano de ANMAT, op. cit. 
ANMAT a fiscalização de drogarias e farmácias (que na Cidade de Buenos Aires incumbe à Direção Nacional de Registro e Fiscalização) nem inclui a função de seguimento de preços. Embora essa função pudesse ser exercida pelo Ministério da Saúde, conforme o disposto na lei de Ministérios, hoje ela é exercida pela Secretaria de Comercio, como sobre qualquer outro produto(24).

Outro dos principais problemas que enfrenta o organismo é a demora na tramitação do registro de medicamentos, prevista normativamente entre 120 e 180 dias, mas que, de fato, pode ser duplicada. Ele tem, também, dificuldades de financiamento, já que os recursos orçamentários que recebe se mantêm estáveis, e, por isso, os recursos próprios, que são produto das tarifas que recebe estão aumentando em relação àqueles.

Outro grande desafio é a retenção do pessoal. Os baixos salários pelo perfil técnico profissional de seus agentes, considerando que $50 \%$ de sua estrutura permanente é profissional, favorecem que sejam captados pela indústria ${ }^{(25)}$. Isso indica que as normas, como a Lei de Ética Pública para prevenir a captura pelo regulado, não estão sendo efetivas ou que o cumprimento do marco jurídico está sendo condicionado pelo tipo de vínculo que se estabelece com as pessoas que efetivamente prestam seus serviços no organismo, já que muitas vezes se trata de bolsistas.

A independência de toda agência regulatória é de grande relevância e medi-la não é uma tarefa fácil, mas com uma análise descritiva podemos dizer que mesmo a criação via decreto da ANMAT a deixa independente, ligando-a mais ao Poder Executivo. Ela comparte esta característica com outros entes extrassetoriais como ENARGAS; ENRE ou CNT(26). Porque desenhada como ente autárquico, ela tem flexibilidade para tomar decisões quanto ao emprego, salários, despedidas e pode receber recursos captados pelo regulador e normativamente, e sua autoridade goza de estabilidade. De fato, nos últimos anos foi dirigida por interventores designados pelo Poder Executivo Nacional, o que facilita a receptividade pelo poder político. Deve-se notar, entretanto, que o programa de pesquisa de medicamentos, por exemplo, expõe tal administração ao lobby das empresas do setor.

Por outra parte, é claro que as funções da ANMAT se concentram na habilitação de estabelecimentos, registro de produtos, fiscalização e controle e a vigilância com a detecção precoce de eventos adversos e/ou inesperados. Surge, então, uma particularidade destacável vinculada às notificações ao sistema de farmacovigilância: mesmo tratadas com confidencialidade elas não respondem a quem efetua tal denúncia. Os relatórios de profissionais ou

(24) BARBIERI, Eugenia; BUMBAK, Sonia y PERALTA Martín. op. cit.

(25) Id. Ibid.

(26) SIFONES, Domingo. op. cit. 
consumidores não são devolvidos pelo organismo com notas diretas informando o resultado do atuado ao denunciante, ainda quando a ANMAT tenha adotado medidas concretas vinculadas à denúncia. $\mathrm{O}$ exposto é corroborado na Carta-Compromisso com o Cidadão, que apesar de se centrar nos destinatários dos serviços - os cidadãos - não tem previsão sobre o particular.

Chama a atenção que não obstante as múltiplas análises que assinalam que os profissionais da saúde deveriam comprometer-se mais com os relatórios para o sistema, este seja ainda um item pendente para a instituição e esteja refletindo uma questão mais complexa e profunda. Ele dá conta de que a efetividade da função regulatória e fiscalizadora da ANMAT, medida em seu impacto referido ao cumprimento de garantir a qualidade, seguridade e eficácia dos medicamentos, está ligada à articulação de interesses, de modo a ser acessível aos consumidores. Esse atributo de acessibilidade à comunidade não está sendo priorizado, resultando impossível afastá-lo da garantia de acesso aos medicamentos, a que a ANMAT também deve contribuir.

Em suma, o principal desafio de um organismo tão técnico é a melhora da acessibilidade da população em geral, tanto para participar no processo de tomada de decisões e fixação de prioridades como no de prestação de contas. Nenhum dos dois atributos foi definido como essencial pela organização aqui analisada. Assim ela se desvincula, também, dos compromissos que assume com os cidadãos na Carta-Compromisso respectiva ${ }^{(27)}$.

A ausência de sistemas de consulta formal influi sobre a independência do ente, pois, na medida em que exista participação no processo de tomada de decisões, se espera será melhor a percepção do público sobre o ente regulador e sua posição ante as empresas reguladas e o poder político(28). Não se registra no funcionamento da ANMAT um mecanismo de audiências públicas, como existem, por exemplo, na Superintendência de Serviços de Saúde, não obstante ambos os organismos dependam da mesma carreira sanitária.

Além dos momentos em que houve intervenção, como o atual, a ANMAT foi pensada para ser dirigida como um ente independente, com um Diretor concursado. Como notam alguns autores, porém, a repartição de trabalho entre uma agência reguladora de mercado (independente) e um organismo dependente diretamente do governo (dependente), encarregado de definir as políticas públicas setoriais, não necessariamente será o melhor em termos institucionais. Às vezes essa distinção clara de funções pode gerar mais problemas do que soluções. Idealmente o melhor seria que cada um deles tenha interiorizada a lógica do outro e comparta um marco de objetivos públicos comuns ${ }^{(29)}$.

(27) CUARTA Carta Compromiso con el Ciudadano. de ANMAT, cit.

(28) SIFONES, Domingo. op. cit.

(29) SANCHO, David. op. cit. 
É precisamente essa articulação que, mais além da excelência técnica da ANMAT, lhe exige assumir como ente do Estado sua função como nivelador e redistribuidor de bens sociais. Isso - face ao alto grau de competitividade entre atores e cenários políticos também altamente fragmentados e situações tão assimétricas de poder, como são as questões de saúde - Ihe impõe garantir não apenas qualidade, mas a equidade no acesso, potencilizando os indivíduos credores de direitos, pondo à sua disposição mecanismos genuínos de intervenção e/ou participação na gestão.

Esta análise é uma caracterização de uma agencia semiautônoma, que depende por uma ou outra razão de uma instância de governo (que no caso da ANMAT, é o Ministério de Saúde da Nação), que tem reconhecido prestígio técnico. Ainda devem ser avaliadas suas decisões para verificar se foram ou não influenciadas por grupos de pressão, uma vez que sua autonomia é condição necessária, mas não suficiente para que a atividade reguladora se realize adequadamente. Isso sem prejuízo da influência sobre seu funcionamento que pode ter, também, a qualidade institucional do Estado. É preciso, portanto, avaliar se tais avanços representaram melhoras no acesso dos consumidores: ver como a ANMAT influiu no desempenho da atividade reguladora da autoridade sanitária, como se articulou com ela, como a retroalimentou com base em seus achados por meio de sua função fiscalizadora. $\mathrm{E}$, nesse caso, verificar se a nova normativa ditada aumentou a qualidade, seguridade, eficácia e a acessibilidade aos medicamentos, para tornar efetivo o direito à saúde dos argentinos.

\section{REFERÊNCIAS BIBLIOGRÁFICAS}

BARBIERI, Eugenia; BUMBAK, Sonia y PERALTA Martín. ANMAT-INPI Organización, estructura y experiencias internacionales. Com coordenação de Daniel Maceira. Buenos Aires: CIPPEC, 2008

CUARTA Carta Compromiso con el Ciudadano de ANMAT. Argentina, 2007.

DONATO, Nora. ANMAT, la descentralización institucional en el ejercicio de la función de regulación y fiscalización. Las agencias. Ponencia presentada en Curso Taller Internacional de Derecho Sanitario. Fortalecimiento de la Función Regulatoria de Salud., OPS- CEPEDISA- FIOCRUZ, Brasilia, 9-13 jun. 2008.

La salud pública en las Américas: nuevos conceptos, análisis de desempeño y bases de acción. Publicación Científica y Técnica, n. 589. Washington, D. C.: OPS/OMS, 2002.

OPS y USAID. Función rectora de la Autoridad Sanitaria Nacional: desempeño y fortalecimiento. Edición Especial n. 17. Washington, D. C., 2007. 
OPS/OMS Reunión para la Creación de la Red Latinoamericana de Autoridades de Salud Pública en Regulación y Fiscalización (REGSALUD). Celebrada en La Habana, Cuba, el 22-23 mar. 2007, con la participación de Argentina, Colombia, Cuba, El Salvador, Honduras, Nicaragua y Paraguay.

PROBST, Jeacqueline Marie; MADIES, Claudia Viviana. Fortalecimiento de la rectoría de la autoridad sanitaria nacional: evaluación y fortalecimiento de la regulación y de fiscalización (versión preliminar). Coordinado por Mónica Bolis. Washington D. C.: OPS Area de Sistemas y Servicios de Salud, 2008.

SANCHO, David. Regulación y agencias reguladoras independientes: elementos claves para la consolidación de su diseño institucional. Ponencia presentada en el VIII Congreso Internacional. Reforma del Estado y Administración Pública. CLAD. Panamá. 28-31 Oct. 2003.

SIFONES, Domingo. Regulación económica y agencias regulatorias independientes: una revisión de la literatura. Revista Virtual Contribuciones a la Economía. Disponível em: <http://eumed.net/ce/ds-regulat.htm> 